\title{
ALUNOS COM AUTISMO NA ESCOLA COMUM: EIS A QUESTÃO
}

\author{
ESTUDIANTES CON AUTISMO EN LA ESCUELA COMÚN: ESTA ES LA PREGUNTA
}

STUDENTS WITH AUTISM IN THE COMMON SCHOOL: THIS IS THE QUESTION

\author{
Ivonete FERREIRA DA SILVA ${ }^{1}$ \\ Mirlene Ferreira Macedo DAMÁZIO²
}

RESUMO: Questões sobre alunos com autismo vêm sendo discutidas há mais de 60 anos, porém a educação escolar ainda tem muito a fazer em prol deles. Em busca das elucidações pertinentes a esse assunto, procuramos compreender os alunos com autismo e as dificuldades que envolvem a escola. Assim, foi realizado o presente estudo bibliográfico com seu recorte temporal de quatorze publicações em livros e periódicos a partir de 2009, visto que em 2008 ocorreu a implantação da política da Educação Especial na perspectiva inclusiva. Estudamos brevemente a trajetória histórica e apresentamos as contribuições existentes sobre a temática, esclarecendo quais as os obstáculos apontados pelos estudiosos e pesquisadores para incluir o aluno com autismo na escola comum, enfatizando os empecilhos e o que se pode fazer para resolver essa questão. Na bibliografia revisitada e investigada, encontramos importantes informações e orientações envolvendo: a mudança de concepção dos currículos escolares; a necessidade de formação continuada de professores; o entendimento do perfil de aluno com TEA; a organização do corpo docente de forma diferente, envolvendo professores e apoio escolar.

PALAVRAS-CHAVE: Aluno com autismo. Escola inclusiva. Professor.

RESUMEN: Las preguntas sobre los estudiantes con autismo se han discutido durante más de 60 años, pero la educación escolar todavía tiene mucho que hacer por ellos. En busca de las explicaciones relevantes sobre este tema, tratamos de comprender a los estudiantes con autismo y las dificultades que rodean a la escuela. Así, este estudio bibliográfico se realizó con su marco temporal de catorce publicaciones en libros y publicaciones periódicas desde 2009, ya que en 2008 se implementó la política de Educación Especial en la perspectiva inclusiva. Estudiamos brevemente la trayectoria histórica y presentamos las contribuciones existentes sobre el tema, aclarando los obstáculos señalados por académicos e investigadores para incluir al estudiante con autismo en la escuela común, enfatizando los obstáculos y lo que se puede hacer para resolver este problema. En la bibliografía revisada e investigada, encontramos información importante y pautas que involucran: el cambio de concepción de los currículos escolares; la necesidad de continuar la formación del profesorado; entender el perfil del estudiante con TEA; La organización de la facultad de manera diferente, involucrando maestros y apoyo escolar.

\footnotetext{
${ }^{1}$ Universidade Federal da Grande Dourados (UFGD), Dourados - MS - Brasil. Graduação em Pedagogia pela Universidade Federal da Grande Dourados. E-mail: ivonetebotelho@hotmail.com

2 Universidade Federal da Grande Dourados (UFGD), Dourados - MS - Brasil. Doutora. Professora da Faculdade de Educação da UFGD. Pesquisa Passo a Passo. ORCID: http://orcid.org/0000-0001-744492261.Email:psmirlenefm@gmail.com
} 
PALABRAS CLAVE: Estudiante con autismo. Escuela inclusiva. Profesor.

ABSTRACT: Questions about students with autism have been discussed for over 60 years, but school education still has much to do for them. In search of the pertinent elucidations on this subject, we tried to understand the students with autism and the difficulties that surround the school. Thus, this bibliographic study was conducted with its timeframe of fourteen publications in books and periodicals from 2009, since in 2008 the implementation of the Special Education policy in the inclusive perspective. We briefly study the historical trajectory and present the existing contributions on the subject, clarifying the obstacles pointed out by scholars and researchers to include the student with autism in the common school, emphasizing the obstacles and what can be done to solve this issue. In the revisited and investigated bibliography, we find important information and guidelines involving: the change of conception of school curricula; the need for continuing teacher education; understanding the student profile with ASD; the organization of faculty differently, involving teachers and school support.

KEYWORDS: Student with autism. Inclusive school. Teacher.

\section{Introdução}

Segundo as leis brasileiras, a inclusão escolar é um princípio constitucional e deve acontecer sem discriminação, devendo, assim, matricular todas as crianças e jovens na faixa etária de 4 a 17 anos, indistintamente. A inclusão escolar é garantida nas leis brasileiras, mas sua aplicação ainda é uma realidade bem distante. Sabemos que o Decreto n. ${ }^{\circ}$ 6.094/2007 apresenta regulamentação para o trabalho do professor, contudo muitas questões envolvendo as barreiras estruturais e atitudinais precisam ser analisadas e revistas, principalmente sobre a formação de professores para atuarem em favor de uma escola aberta a todas as diferenças.

Muitos são os entraves e empecilhos para a escola se tornar aberta às diferenças de todos, e sobre alunos com autismo os questionamentos são muitos, ora pelas famílias, ora por professores e gestores. As dúvidas precisam ser respeitadas, analisadas e medidas pontuais devem ser propostas. Isso demanda novos engenhos pedagógicos e administrativos, envolvendo desde a formação dos professores e a organização didática pedagógica das escolas.

Segundo Damázio (2005), a cultura de cada tempo baseia-se em concepções de acordo com o padrão de normalidade, definido para justificar a aceitação, a eliminação, a exploração e o assistencialismo em favor das pessoas, legitimando as atitudes praticadas. Durante muitos séculos, a história nos mostrou que a exclusão das pessoas com deficiência foi legitimada e as práticas sociais comprometidas. A falta de humanidade e respeito às pessoas com deficiência se estendeu por vários períodos da história. Em razão das diversas atrocidades cometidas às 
pessoas com deficiência, estas passaram de exploradas para exploradoras de si mesmo, oficializando a mendicância.

A partir do século XIX, as pessoas com deficiência passaram a ser reconhecidas. Isso se deu por meio de várias manifestações de setores importantes da sociedade, enfatizando a área médica e educacional, que começaram a observar que pessoas consideradas incapazes de aprender poderiam desenvolver grandes habilidades. Muitas dificuldades foram enfrentadas para que fossem criadas condições educacionais para pessoas com deficiência.

De acordo com Damázio (2005), no início desse processo educacional em favor de pessoas com deficiência, os métodos de ensino eram realizados de maneira intuitiva, não formal, geralmente em princípios tradicionais e/ou tecnicistas. As conquistas na área da educação da pessoa com deficiência foram ocorrendo de forma gradativa e lenta, e fica notório que isso aconteceu apenas porque houve desenvolvimento também na educação de modo geral. Somente em meados do século XX, foram identificados avanços na questão da integração escolar das crianças consideradas "especiais", despontando teorias importantes com novas concepções e princípios. Assim, novas propostas surgiram, organizando de forma diferente os serviços educacionais da Educação Especial.

Saber que as pessoas com alguma deficiência eram capazes de aprender não era mais suficiente. A investigação tomou uma proporção maior, unindo qualidade de vida com autonomia, acreditando que pessoas com deficiência podiam desenvolver habilidades e integrar-se na sociedade. Essa forma, então, gerou nas políticas públicas, no País e nos profissionais da área da educação indignação, os quais passaram a buscar os direitos das pessoas com deficiências, não aceitando mais discriminações, preconceito e rejeição e estabelecendo os princípios inclusivos.

Portanto, a educação inclusiva consiste em pôr em prática a educação acessível a todas as pessoas. Para realizar a inclusão, é preciso compreender as diferenças humanas, valorizando os potenciais, assegurando que as diferenças sejam respeitadas como limites e possibilidades naturais de qualquer um, e não por meio de estigmas como déficit, falhas, faltas ou deficiências. Enfim, uma sociedade que estimula a participação de cada um, que aprecia as diferentes experiências humanas e reconhece o potencial de todo cidadão.

\section{Eis a Questão das Pessoas com Autismo!}

No que diz respeito às pessoas com autismo, podemos perceber que ocorreram várias mudanças no conceito e diagnósticos no decorrer da história. Uma das primeiras publicações se deu em 1908, por Eugen Bleule, que desenvolveu uma teoria de que as o autista apresentava uma vasta imaginação e sua condição estava ligada à esquizofrenia. Essa teoria 
seria contraditória com a descrição de Kanner Queem, que em 1943 publicou um artigo intitulado "Distúrbios autísticos do contato afetivo", em que defendia a ideia de que o comportamento do autista de isolamento seria algo desenvolvido ainda no nascimento das crianças. O autor chegou a essa conclusão após observações feitas com onze crianças, com características semelhantes, com caso de autismo severo. A partir do estudo de Kanner, outros pesquisadores passaram também a fazer seus registros, procurando encontrar conceitos para caracterizar os autistas (KLIN, 2006). Orrú (2012) nos diz que a incapacidade para estabelecer relações com as pessoas, conjunto de atrasos, alterações na aquisição, no uso da linguagem e uma obsessão em manter o ambiente intacto e tendência a repetir uma sequência limitada de atividades ritualizadas são características encontradas em diagnóstico de pessoas com autismo.

Em 1944, o médico de Viena, Hans Asperger, publica um artigo com o título "Psicopatologia autística na infância". Diferente de Kanner, ele diz que o autismo tem como causa uma deficiência biológica, uma má formação genética. Esse trabalho de Asperger esteve em anonimato até 1980. Após essa data, Lorna Wing passou a fazer comparações entre os dados estabelecidos por ele com o manual Diagnóstico e Estatístico de Transtorno Mental V (DSM-V), e delimitou o Transtorno Autista como Transtorno do Espectro Autista (TEA), buscando caracterizá-lo por transtornos no neurodesenvolvimento, tendo dificuldades de se comunicar e interagir socialmente, mantendo condutas repetitivas (KLIN, 2006).

Nos anos 1960, Michael Rutter fazia comparações entre a biologia do indivíduo e a genética, trazendo grandes contribuições para o entendimento da natureza biológica do autista. Na Classificação Internacional de Doenças, CID 9, só foi oficializada em 1975, considerada psicose da infância. Em 1978, Ruther propôs que o autismo fosse compreendido como perturbação do desenvolvimento, podendo levar em conta os padrões restritos e repetitivos. Em 1989, Friter coloca o autismo como uma deficiência mental, cujo diagnóstico pode ser dado a partir dos três anos de idade, tendo como características peculiares a falta de comunicação, a interação social e as estereotipias, com uma lacuna no contato afetivo, e que essas dificuldades podem aumentar atingindo seu pico maior na idade escolar.

Martins (2012) retrata que Bruno Bettelheim, no século XX, deu ênfase à ideia da teoria das mães frigoríficas, dizendo que a falta de afeto era fator determinante para que o aluno desenvolvesse autismo. Portanto, nesse período, segundo a autora, muitos filhos foram separados das mães.

Na atualidade, Martins (2012) diz que o autismo é um espectro de Síndromes, de difícil entendimento, mas que tem despertado, ao longo do tempo, muita curiosidade, podendo comprovar essa questão pelo número cada vez maior de pesquisas. 
Schwartzman e Araújo (2011) enfatizam que tais dificuldades são problemas neurológicos, não apenas clínicos. Nesse contexto, os autores procuram esclarecer que o diagnóstico do TEA, muitas vezes, está sendo feito precocemente. Eles chamam a atenção ao fato de que nem toda teoria que está sendo aplicada é verdadeira, e em alguns casos não existe respaldo científico.

As pessoas com transtornos do espectro autista têm necessidades em vários aspectos do desenvolvimento, e as propostas tanto terapêuticas como pedagógicas precisam atendêlas. Nos dias atuais, ainda é muito questionada a teoria afetiva, pois acredita-se que somente pela observação dos modos de agir não é fator preponderante para se fechar um diagnóstico.

Santos (2008) menciona que a educação é de extrema importância e colabora com a investigação diagnóstica, em virtude de ser o primeiro lugar de interação social da criança fora do contexto familiar. É onde a criança vai ter maior dificuldade de se adaptar às regras sociais. Diante do exposto, muito se tem a estudar para compreender esse ser humano, bem como as formas de se trabalhar com ele na família e na escola, assegurando seu desenvolvimento e aprendizagem, garantindo-lhe vida cidadã. Assim, realizamos este estudo por meio da pesquisa bibliográfica, a partir de investigações em livros e artigos científicos. Nesta pesquisa, buscou-se estudar e compreender os alunos com autismo com relação ao trabalho no ambiente escolar, envolvendo a atividade do professor em uma perspectiva inclusiva. Assim, procuramos, na produção científica da área, as pesquisas e estudos já realizados que orientam o trabalho com esse perfil de aluno na escola de ensino regular, principalmente após a publicação da Política Nacional de Educação Especial em uma perspectiva inclusiva.

\section{A Pesquisa}

Realizamos uma pesquisa bibliográfica de caráter qualitativo. O levantamento bibliográfico foi a partir de 2009. Foram utilizados os seguintes descritores para realizar a investigação: escola comum e aluno com autismo, inclusão de aluno com autismo na sala de aula comum. Realizamos a investigação em banco de dados de teses e dissertações da Coordenação de Aperfeiçoamento de Pessoal de Nível Superior, na Biblioteca Digital Brasileira de Teses e Dissertações, bem como em revistas, periódicos e livros que pudessem abordar a temática. Encontramos quatorze estudos que abordaram a questão dos alunos com autismo e o trabalho no ambiente escolar, envolvendo a atividade do professor em uma perspectiva inclusiva. No decorrer das leituras, fizemos detalhamentos das referências, procurando demarcar os aspectos relevantes que nos ajudassem a compreender a temática em questão. 
O primeiro estudo foi sobre A perspectiva de professores quanto ao trabalho com crianças com autismo, de Ana Gabriela Lopes Pimentel e Fernanda Dreux Miranda Fernandes, trabalho realizado em 2009. O estudo de Pimentel e Fernandes (2009) apontou que, por meio de questionário aplicado a professores sobre as questões da inclusão dos alunos autistas em sala de aulas comum, os professores precisam buscar novos conhecimentos para trabalharem com uma sala na visão heterogênea, não somente para lidar com o aluno autista, mas também com as especificidades de todos os alunos. As diferenças dos alunos não são contempladas e todos ficam prejudicados. Existem muitas questões pedagógicas inadequadas que prejudicam os alunos de maneira geral, e não apenas os alunos com autismo. Entretanto, os alunos com autismo precisam de tempo e ritmos diferenciados para realizar as atividades, bem como acompanhamentos individuais respeitando suas especificidades enquanto diferença humana.

A pesquisa Inclusão escolar de alunos com autismo, de Marise Suplino, realizado em 2009. A autora buscou elucidar questões referentes à inclusão escolar das pessoas com TEA. Segundo a referida autora (2009), a escola brasileira ainda se comporta de forma excludente, pois está preestabelecido nas leis que o aluno autista tem o seu direito garantido de estar devidamente matriculado na rede regular de ensino, mas no contexto em geral percebemos que a escola possui grande dificuldade para lidar com as diferenças, principalmente do aluno com TEA. O aluno não se desenvolve não pela sua especificidade comportamental, mas pela deficiência das práticas e ações pedagógicas. A escola não compreende as diferenças e os professores não são preparados em suas formações iniciais e continuadas. Os alunos com autismo ficam à deriva, não desenvolvendo seu potencial. A escola não respeita a diferença do aluno com autismo. Os professores não são qualificados e o ensino fica a desejar, provocando déficit no aprendizado.

A inclusão de alunos com autismo na escola regular: quando o campo é quem escolhe a teoria de Dayse Serra, realizado em 2010. De acordo com Serra (2010), as políticas públicas contribuem de forma significativa na questão da inclusão escolar, envolvendo: a Declaração Universal dos Direitos Humanos (1948) e a Lei n. ${ }^{\circ}$ 9.394, de Diretrizes e Bases da Educação (1996). Essas leis discutem, na realidade, uma educação pautada por um conhecimento para todos. No caso do aluno autista, só a normatização não é capaz de nortear todo o seu conhecimento, temos que estar atentos para atender a especificidade de cada aluno. De acordo com o estudo, não estão sendo contempladas as diferenças desses alunos, envolvendo o modus operandis da escola.

A Inclusão das crianças autistas, um estudo de natureza qualitativa e quantitativa de Maria Tereza Vieira Lopes, realizado em 2011. A autora enfatiza que a legislação brasileira 
sofreu muitas transformações no decorrer dos tempos, colaborando para o aumento significativo da responsabilidade escolar na questão da inclusão, dando ênfase à inclusão das pessoas autistas. Entretanto, de nada servem belas e tracejadas leis, se não ocorrem mudanças reais no dia a dia da escola. A escola precisa transformar suas práticas pedagógicas de excludentes em includentes. Também existem métodos que precisam ser introduzidos no cotidiano do fazer da escola, assegurando ações heterogêneas. Os alunos com autismo não se desenvolvem por falta de condições específicas e adequadas às necessidades deles. Caso sejam realizadas as condições específicas de acessibilidade pedagógica e comunicacional, muito já poderá ser aperfeiçoado, envolvendo, é claro, a formação dos professores.

Estratégias a utilizar para promover a inclusão escolar de um aluno com autismo, de Vera Lúcia Miranda Pires Morgado, realizado em 2011, traz que o número de alunos com autismo matriculados tem aumentado gradativamente ao longo dos anos, o que demonstra uma maior aceitação das famílias que buscam alternativas para que seus filhos possam se desenvolver também na escola. Salienta que a escola tem procurado cada vez mais se adequar a essa demanda, procurando, por meio das formações continuadas dos professores, maneiras de ensinar um aluno com TEA no contexto da escola regular. Nesse estudo, o foco foi a formação de professores, visto que ela é a mola mestra de condução do processo. Entretanto, se tiver estrutura de apoio ao professor, seu trabalho ficará comprometido para todos os alunos.

O estudo Concepções de professores sobre inclusão escolar e interações em ambiente inclusivo: uma revisão da literatura, de Sônia Regina Fiorim Enumo, Edinete Maria Rosa e Kelly Ambrosio Silveira, realizado em 2011, apresenta as dificuldades encontradas pelos docentes para trabalharem com alunos com necessidades específicas, encontrando barreiras no currículo, na estrutura física e atitudinais dos profissionais, envolvendo a instituição escolar, dificultando, assim, o trabalho do professor para atuar de forma diferenciada com seus alunos. Nesse aspecto, o aluno com autismo fica prejudicado em seu desenvolvimento, em face das várias limitações da escola, e o desejo, portanto, é que esses alunos não sejam matriculados. A escola fica impotente com tantos empecilhos que desencadeiam diversas impossibilidades no cotidiano pedagógico.

A pesquisa Uma reflexão acerca da inclusão de alunos autista no ensino regular, de Élida Tamara Prata de Oliveira Praça, realizado em 2011, nos diz que para realmente acontecer a inclusão, várias mudanças precisam ocorrer, tanto no espaço físico quanto nas formas de agir dos profissionais da escola, procurando compreender as diversas maneiras de ensinar e aprender. Os docentes precisam buscar formações para trabalharem, utilizando 
estratégias pedagógicas e adequações de materiais específicos e diferenciados a fim de atender a demanda da sala de aula comum, descaracterizando certas barreiras e preconceitos.

O estudo Estado da arte sobre inclusão escolar de alunos com transtorno do espectro autismo no Brasil, de Juliana de Oliveira e Cristiane Silvestre de Paula realizado em 2012, traz que políticas públicas brasileiras e internacionais têm contribuído para que o aluno com autismo seja incluído na sala de aula e que sua diferença possa ser respeitada na instituição escolar. No entanto, entendemos também que somente a existência de normas jurídicas em favor da inclusão não faz com que ela aconteça, pois devemos perceber que a diferença acontece quando há o engajamento e vontade de toda a equipe escolar. As autoras alegam que as leis determinam, mas, para as mudanças realmente se efetivarem, é preciso que o modelo formador dos professores envolva com pontualidade os paradigmas inclusivos, nos quais não só uma mudança de mentalidade, mas também de condutas e comportamentos nos modos de pensar e fazer.

A pesquisa Face a face com o autismo: será a inclusão um mito ou uma realidade? de Cláudia Paiva Martins, realizado em 2012, mostra, que as escolas com concepção inclusiva podem combater o preconceito. Portanto, o estudo enfatiza a inclusão do autista com os seus pares, demonstrando o quanto é proveitoso para ambos estarem juntos. Salienta que, para a escola comum manter uma concepção inclusiva, precisa estar aberta a novos diálogos, buscando adequar o currículo e toda a estrutura pedagógica e, dessa forma, fazer a diferença e garantir um ambiente que não seja segregador.

Análise institucional do discurso de professores de alunos diagnosticados como autistas em inclusão escolar, de Isabel de Barros Rodrigues, Luiz Eduardo de V. Moreira e Rogério Lerner, realizado em 2012, exemplifica as dificuldades encontradas na escola com a questão da inclusão, pois são poucos os professores que aceitam trabalhar com essa perspectiva, enfatizando o diferente e a diferença. No caso da inclusão do aluno autista, isso se torna mais comprometedor, pois professores e escola precisam estar preparados para trabalharem a rotina e aos métodos fundamentais para o desenvolvimento pedagógico.

Já o estudo A inclusão escolar de um aluno com autismo: diferentes tempos de escuta, intervenção e aprendizagens de Carla Andréa Brande e Camila Cilene Zanfelice, realizado em 2012, apresenta que as autoras enfrentaram vários empecilhos e necessitaram da ajuda de alguns profissionais para melhor compreender o processo envolvendo o aluno com autismo na sala de aula regular. Realizaram muitas reflexões, procurando estratégias para resolver os desafios encontrados, pois em vários momentos o aluno não respondia de forma positiva às exigência impostas pela participação em uma classe comum. $\mathrm{O}$ estudo apresenta importantes dados sobre as dificuldades e possibilidade de aluno autista estar em sala de aula regular. É 
preciso respeitar as diferenças desse aluno, garantindo o que é específico de acordo com sua necessidade.

Na pesquisa intitulada Inclusão escolar de alunos com Autismo: quem ensina quem aprende? de Adriana Rodrigues Saldanha de Menezes, realizado em 2013, aponta que o professor da sala comum precisa de preparação para trabalhar com aluno autista e deve buscar compartilhamento, interlocução com o professor especialista, podendo ambos contribuir significativamente para o desenvolvimento do aluno. Enfatiza também a importância do engajamento dos gestores escolares com o processo.

No estudo A Inclusão educacional de pessoas com autismo no Brasil: uma revisão da literatura, de Débora Regina de Paula Nunes, Mariana Queiroz Orrico Azevedo e Carlos Schmidt, realizado em 2013, trazem em sua pesquisa várias políticas públicas favoráveis à questão da inclusão e mencionam que a inclusão no Brasil teve como ponto de partida a Constituição Federal de 1988, como influência de Jomtien 1990 e a Declaração de Salamanca em 1994. Enfatizam que a Educação Especial tem respaldo nas ações governamentais, sendo garantida pela LDBEN/1996 e pela Política Nacional de Educação Especial 2008, assegurando que os alunos com necessidades específicas devem ser matriculados na rede regular de ensino. Salienta que o aluno autista enfrenta dificuldades no processo de inclusão escolar, em virtude da necessidade de qualificação dos professores, construção de estratégias curriculares e pedagógicas. Existe sim, a necessidade de respeitar a diferença desse aluno, garantindo especificidades.

A décima quarta leitura foi sobre a "Inclusão das crianças autistas: um estudo sobre interações sociais no contexto escolar", de Emellyne Lima de Medeiros Dias Lemos, Nádia Maria Ribeiro Salomão e Cibele Shirley Agripino Ramos, realizado em 2014. Busca-se nessa pesquisa relacionar como acontece a inclusão dos alunos autistas na sala de aula comum, como se dá a atuação dos professores mediante o aluno com o transtorno. As autoras mostram as dificuldades envolvendo a formação dos professores, a organização curricular, à dinâmica pedagógica, bem como, o respeito às especificidades desse aluno.

\section{Considerações finais}

Pudemos observar a partir dos referenciais estudados que existem vários empecilhos que norteiam a inclusão do aluno autista na escola regular brasileira. As questões acerca desse tema foram, ao longo desta pesquisa, discutidas por vários estudiosos e pesquisadores, com o intuito de ajudar a encontrar as possibilidades e romper os entraves existentes para efetivar essa perspectiva educacional em favor desse aluno. 
Compreendemos ao longo do estudo que garantir o acesso à escola comum para as pessoas com autismo não é tarefa fácil. Esses alunos têm direito não só ao acesso, mas também à permanência com equidade. Entretanto, constatamos, por meio da pesquisa, que seus direitos não são respeitados plenamente, em virtude de a escola não ter transformado sua concepção educacional. As escolas continuam desenvolvendo seus trabalhos em uma visão ora segregadora, ora integracionista. O mote da inclusão está no plano da retórica, das ideias para todos os seus alunos, inclusive para o público-alvo da educação especial, nesse caso, alunos com autismo.

Analisando os dados levantados pelos autores dos quatorzes referenciais usados como norteadores desta pesquisa bibliográfica, percebemos que são fundamentais para o desenvolvimento do aluno autista: a mudança de concepção dos currículos escolares; a necessidade de formação continuada de professores; o entendimento do perfil de aluno com TEA; a organização do corpo docente de forma diferente, envolvendo professores e apoio escolar. Na sala de aula comum, segundo as pesquisas realizadas, falta organização pedagógica adequada e há pouca ou nenhuma formação para os professores a respeito da inclusão dessas crianças.

Para que se possam resolver os vários entraves na inclusão do aluno com autismo, percebemos que a formação específica e continuada dos professores é primordial e urgente, pois assim poderão desenvolver um trabalho adequado às necessidades do aluno autista, contribuindo com o seu aprendizado, efetivando o que é garantido pelas leis. Precisamos de professores que busquem repensar os seus conhecimentos já adquiridos em suas experiências ou campo acadêmico e ter informação prévia sobre como fazer o aprendizado se efetivar. É imprescindível que a escola faça adequações pedagógicas, procurando contribuir com o desenvolvimento e aprendizado desse aluno. Para que isso ocorra, é fundamental um olhar diferenciado sobre a pessoa com autismo, que não pode ser considerada incapacitada, e sim como cidadã que pensa e aprende.

\section{REFERÊNCIAS}

APA. Manual diagnóstico e estatístico de transtornos mentais - DSM-V. Tradução Maria Inês Corrêa Nascimento et al. Revisão técnica Aristides VolpatoCordioli et al. 5. ed. Porto Alegre: Artmed, 2014.

BENNETT, Tess et al. Putting inclusion into practice: perspectives of teachers and parents. Exceptional Children, v. 64, n. 1, p. 129, 1997.

BRAGA, Carolina da Conceição Silva. Perturbações do espectro do autismo e inclusão: atitudes e representações dos pais, professores e educadores de infância. 2010. 130 f. Tese 
(Doutorado) - Curso de Mestrado em Educação Especial, Universidade do Minho Instituto de Educação, Portugal, 2010.

BRANDE, Carla Andréa; ZANFELICE, Camila Cilene. A inclusão escolar de um aluno com autismo: diferentes tempos de escuta, intervenção e aprendizagens. Educação Especial, Santa Maria, v. 25, n. 42, p. 43-56, abr. 2012.

\section{BRASIL. [Constituição (1988)]. Constituição da República Federativa do Brasil: promulgada em 5 de outubro de 1988. 4. ed. São Paulo: Saraiva, 1990.}

BRASIL. Decreto n ${ }^{\circ} 6.094$, de 24 de abril de 2007. Dispõe sobre a implementação do Plano de Metas Compromisso Todos pela Educação, pela União Federal, em regime de colaboração com Municípios, Distrito Federal e Estados, e a participação das famílias e da comunidade, mediante programas e ações de assistência técnica e financeira, visando à mobilização social pela melhoria da qualidade da educação básica. Diário Oficial da União. 25 abr. 2007a.

BRASIL. Lei n. 12.796, de 4 de abril de 2013: altera a Lei n. 9.394 de 20 de dezembro de 1996, que estabelece as diretrizes e bases da educação nacional, para dispor sobre a formação dos profissionais da educação e dar outras providências. Brasília: Planalto Central, 2013.

BRASIL. Ministério da Educação. Secretaria de Educação Especial (SEESP). Política Nacional de Educação Especial na Perspectiva da Educação Inclusiva. Brasília: MEC/SEESP, 2008CAMARGO, Síglia Pimentel Höher. Competência social, inclusão escolar e autismo: revisão crítica da literatura. 2009. 10 f. TCC (Graduação) - Curso de Psicologia, Universidade Federal do Rio Grande do Sul, Porto Alegre, 2009.

BRASIL. LDB - Leis de Diretrizes e Bases. 1996. Disponível em: http://portal.mec.gov.br/seed/ arquivos/pdf/tvescola/leis/lein. Acesso em: 1. dez. 2017

CARNEIRO, Relma Urel Carbone. Educação inclusiva na educação infantil. Práxis Educacional, Vitória da Conquista, v. 8, n. 12, p. 81-95, jan./jun. 2012.

COHEN, Louis et al. Research methods in education. [s.1.]: Taylor and Francis, 2003.

DAMÁZIO, Mirlene F. Macedo. Pessoas com deficiência e as concepções subjacentes a sua existência: das comunidades primitivas ao pós-moderno. Cadernos Unitri, Uberlândia, v. 2, n. 2, p. 10-35, fev./mar. 2005.

ENUMO, Sônia Regina Fiorim; ROSA, Edinete Maria; SILVEIRA, Kelly Ambrosio. Concepções de professores sobre inclusão escolar e interações em ambiente inclusivo: uma revisão da literatura. Revista da Literatura, Espírito Santo, v. 18, n. 4, p. 685-708, maio 2012.

GONÇALVES, Mendes Enicéia. Breve histórico da educação especial no Brasil. Revista Educación y Pedagogía, Medellín, Universidad de Antioquia, Facultad de Educación, v. 22, n 57, p. 93-109, mayo/ago. 2010.

KLIN, Ami. Autismo e síndrome de Asperger: uma visão geral. Revista Brasileira Psiquiatria, São Paulo, v. 28, n. 1, 2006.

LEMOS, Emellyne Lima de Medeiros Dias; SALOMÃO, Nádia Maria Ribeiro; RAMOS, Cibele Shirley Agripino. Inclusão de crianças autistas: um estudo sobre interações sociais no contexto escolar. Inclusão de Crianças Autistas, Paraíba, v. 20, n. 1, p. 117-130, mar. 2014. 
LOPES, Maria Tereza Vieira. Inclusão das crianças autistas. 2011. 232 f. Dissertação (Mestrado) - Curso de Mestrado em Educação Especial, Escola Superior de Educação Almeida Garrett, Lisboa, 2011.

MARTINS, Cláudia Paiva. Face a face com o autismo: será a inclusão um mito ou uma realidade?. 2012. 255 f. Dissertação (Mestrado) - Curso de Ciências da Educação, Escola Superior de Educação João de Deus, Lisboa, 2012.

MENEZES, Adriana Rodrigues Saldanha de. Inclusão escolar de alunos com autismo: quem ensina e quem aprende? In: VIII ENCONTRO DA ASSOCIAÇÃO BRASILEIRA DE PESQUISADORES EM EDUCAÇÃO ESPECIAL. Anais..., 8., 2013, Rio de Janeiro. Londrina: Editora Mediação, 2013. p. 2743-2751.

MORGADO, Vera Lúcia Miranda Pires. Estratégias a utilizar para promover a inclusão escolar de um aluno com autismo. 2011. 167 f. Dissertação (Mestrado) - Curso de Mestrado em Educação Especial, Escola Superior de Educação Almeida Garrett, Lisboa, 2011.

NUNES, Débora Regina de Paula; AZEVEDO, Mariana Queiroz Orrico; SCHMIDT, Carlos. Inclusão educacional de pessoas com autismo no Brasil: uma revisão da literatura. Revista Educação Especial, Santa Maria, v. 26, n. 47, p. 557-572, dez. 2013.

OLIVEIRA, Juliana de; PAULA, Cristiane Silvestre de. Estado da arte sobre inclusão escolar de alunos com transtornos do espectro do autismo no Brasil. Cadernos de Pós-graduação em Distúrbios do Desenvolvimento, São Paulo, p. 53-65, maio 2012.

ORRÚ, Silvia Ester. Autismo, linguagem e educação: interação social no cotidiano escolar. Rio de Janeiro: Wak, 2012.

PIMENTEL, Ana Gabriela Lopes; FERNANDES, Fernanda Dreux Miranda. A perspectiva de professores quanto ao trabalho com crianças com autismo. 2009. 8 f. Dissertação (Mestrado) - Curso de Ciências da Reabilitação, Faculdade de Medicina, São Paulo, 2009.

PRAÇA, Élida Tamara Prata de Oliveira. Uma reflexão acerca da inclusão de aluno com autismo no ensino regular. 2011. 140 f. Dissertação (Mestrado) - Curso de Mestrado Profissional em Educação Matemática, Universidade Federal de Juiz de Fora, Juiz de Fora, 2011.

RODRIGUES, Isabel de Barros; MOREIRA, Luiz Eduardo de V.; LERNER, Rogério. Análise institucional do discurso de professores de alunos diagnosticados como autistas em inclusão escolar. Psicologia: Teoria e Prática, São Paulo, v. 14, n. 1, p. 70-83, abr. 2012. SANTOS, Ana Maria Tarcitano. Autismo: um desafio na alfabetização e no convívio escolar. São Paulo: CRDA, 2008.

SCHWARTZMAN, José Salomão; ARAÚJO, Ceres. Transtorno do espectro do autismo TEA. São Paulo: Memnon, 2011.

SERRA, Dayse. Sobre a inclusão de alunos com autismo na escola regular: quando o campo é quem escolhe a teoria. Revista de Psicologia, Fortaleza, v. 2, n. 1, p. 163-176, dez. 2010.

SILVA, Otto Marques da. A epopeia ignorada: a pessoa deficiente na história do mundo de ontem e de hoje. São Paulo: Cedas, 1987. 
SUPLINO, D. Marise. Inclusão escolar de alunos com autismo. 2009. Disponível em: http://files.inclusaoescolar.webnode.com.br/200000010-8d32a8e2d2/Inclusao-de-alunos-comautismo.pdf Acesso em: 1. ${ }^{\circ}$ dez. 2017.

UNESCO. Declaração de Salamanca: sobre princípios, políticas e práticas na área das necessidades educativas especiais. Salamanca: Espanha, 1994.

UNESCO. Declaração Mundial sobre Educação para Todos: satisfação das necessidades básicas de aprendizagem. UNESCO: Jomtien, 1990.

\section{Como referenciar este artigo}

SILVA Ivonete Ferreira, e DAMÁZIO, Mirlene Ferreira Macedo. Alunos com autismo na escola comum: eis a questão. Doxa: Rev. Bras. Psico. e Educ., Araraquara, v. 21, n. 2, p. 349-361, jul./dez. 2019. e-ISSN: 2594-8385. DOI: https://doi.org/10.30715/doxa.v21i2.13164

Submetido em: 20/02/2019

Aprovado em: 20/07/2019

Publicado em: 01/08/2019 